\title{
REDES SOCIAIS E ESFERA PÚBLICA: A LEGITIMAÇÃO DA PARTICIPAÇÃO POLÍTICA NO CENÁRIO DEMOCRÁTICO BRASILEIRO
}

\author{
Carolline Leal Ribas ${ }^{1}$ \\ Amaury Silva ${ }^{2}$
}

\section{Resumo:}

O presente trabalho tem como intuito estabelecer um cotejamento entre questão da esfera pública e a ascensão das redes sociais na tentativa de se atribuir legitimidade à participação política mobilizada por novos atores sociais. Para construir este raciocínio, procedeu-se uma análise da emergência de plataformas online, como Facebook, Instagram e Twitter, que possibilitaram o intercâmbio de pensamentos e valores, inclusive no campo da política, com fulcro no cenário das eleições de 2018 no Brasil, na intenção de se fazer um cotejamento com a teoria discursiva-procedimental de Habermas, a fim de se atribuir legitimidade à participação política impulsionada pelas redes sociais.

Palavras-chave: Redes Sociais; Espaço Público; Participação Política; Legitimidade

\section{SOCIAL NETWORKS AND THE PUBLIC SPHERE: A LEGITIMATION OF POLITICAL PARTICIPATION IN THE BRAZILIAN DEMOCRATIC SCENARIO}

\begin{abstract}
:
The present work aims to establish a comparison between the question of the public sphere and the rise of social networks in an attempt to attribute legitimacy to the political participation mobilized by new social actors. For this, an analysis was made of the emergence of online platforms, such as Facebook, Instagram and Twitter, which made it possible to exchange thoughts and values, including in the field of politics, with a focus in the scenario of the 2018 elections in Brazil, in intention to make a comparison with Habermas' discursive-procedural theory, in order to attribute legitimacy to political participation
\end{abstract}

Keywords: social networks; Public place; Political Participation; Legitimacy

\section{Introdução.}

A democracia inicia o século XXI em face de uma grande crise de legitimidade. Em todos os países nos quais ela prosperou, acabou por se degenerar em um sistema políticopartidário meramente formal, no qual parece que os cidadãos não se sentem efetivamente representados pelos eleitos. Seguindo o caminho da distorção já previsto na Grécia Antiga, a

\footnotetext{
${ }^{1}$ Doutora em Humanidades pela Universidade UNIGRANRIO. Mestre em Estudos Culturais. Especialista em Direito Público e em Gestão Pública. Professora de Graduação e Pós Graduação no Centro Universitário Estácio de Sá.

${ }^{2}$ Juiz de direito no Estado de Minas Gerais. Professor da Faculdade de Direito do Vale do Rio Doce (graduação e pós-graduação). Mestre em Estudos Territoriais (ênfase em Criminologia e Direitos Humanos). Autor de obras jurídicas e doutorando em Comunicação.
} 
democracia se transformou em demagogia, de maneira que o sistema eleitoral passou a ser um fim em si mesmo e se governa prioritariamente com o objetivo de assegurar a manutenção do poder. Tal constatação, por si só, já seria devastadora em termos de legitimidade do regime democrático, mas assume uma proporção ainda mais exagerada quando o cidadão se vê diante de uma sociedade na qual a democracia indireta é apontada como a única alternativa, na medida em que se preserva um conceito de participação social na política.

A verdade, porém, é que a discussão a respeito da legitimidade da democracia representativa é apenas uma pequena parte do fato democrático e que a impossibilidade de uma democracia agórica não implica inviabilidade da participação social direta. Para que isso seja viável, entretanto, se faz necessária uma releitura do conceito de democracia e de legitimidade, como forma de se passar a viabilizar a construção de novos espaços públicos, mesmo que estes sejam virtuais, que possam permitir amplo debate entre diversos atores sociais.

Tendo em vista a importância do debate, Jürgen Habermas vai se dedicar a investigar a possibilidade de construção de um espaço público, motivo pelo qual a sua teoria vai ser chamada de procedimental-discursiva, na medida em que se presta a defender a existência de uma série de procedimentos que se destinem a assegurar a ampla participação de todos os interessados nos resultados das deliberações. A ideia é a de que o fundamento de legitimidade do direito não deve ser atrelado à justiça abstrata, mas sim a questões formais consistentes no respeito a um procedimento que permita que os atores sociais tenham amplo acesso ao discurso. A seu ver, para que a esfera pública seja funcional, ela vai ter alguns pressupostos de funcionamento regular e adequado, quais sejam: a) uma base cultural mínima dos participantes; b) uma base democrática de livre expressão da vontade em igualdade de condições; c) uma base mínima de direitos que garantam a liberdade individual; e d) uma base mínima de desenvolvimento moral e liberdade crítica às regras vigentes no jogo político.

Com base nessa perspectiva, o presente trabalho tem como escopo estabelecer um processo de cotejamento entre as redes sociais da internet e a esfera pública, na tentativa de se atribuir legitimidade aos discursos produzidos pela sociedade civil por meio de redes virtuais, em especial Facebook, Instagram e Twitter.

A questão se passa no cenário brasileiro que se instaurou no ano eleitoral de 2018: proliferação de discursos de ódio e de Fake News, além da difusão de Hastags e criação de grupos virtuais a favor e contra os candidatos à Presidência da República. Nota-se que o 
ambiente cibernético foi o fator que permitiu conexão e diálogo entre grupos sociais e Poder Público, o que possivelmente não teria existido se os debates políticos fossem restritos à mídia tradicional.

O desenvolvimento deste trabalho deu-se em três partes. Primeiramente, almeja-se trazer à tona a questão das redes sociais como forma de participação popular no cenário político, com ênfase na formação de grupos institucionalizados e apartidários, e na proliferação de inúmeras Hastags amplamente compartilhadas via Instagram, Facebook e Twitter de cunho político e reivindicatório. Em seguida, recorre-se à doutrina de Habermas, o qual trouxe a noção de esfera pública como local próprio para se debater tanto políticas ligadas à vida cotidiana quanto à política formal em nível estatal. Devido a sua amplitude, a esfera pública é constituída por diversos grupos sociais, o que permite auferir seu papel no fortalecimento da cidadania e da democracia. Por fim, pretende-se atribuir legitimidade às instituições midiáticas sociais, que, embora não sejam formas legítimas de se auferir poder representativo, elas acabam sendo legitimadas socialmente, pois a própria sociedade lhe atribui tal caráter.

O que marca o Estado Democrático de Direito é exatamente a democraticidade do seu direito, de maneira que a participação política direta, mesmo que impulsionada por redes virtuais, não deve ser relegada a um segundo plano, mas, pelo contrário, deve ser tomada como a regra, preservando-se o indivíduo contra a erosão de sua capacidade de influenciar na elaboração das normas das quais será destinatário.

Por fim, ressalta o caráter interdisciplinar desta pesquisa, uma vez que a problematização da emergência de novas redes online como mecanismos de participação social não pode ficar restrita à Ciência do Direito, tendo em vista que os processos midiáticos também podem ser analisados sob a seara da Comunicação Social, que possibilitará compreender o fenômeno social sob as vias da cibercultura. Ainda, falar em legitimidade e deliberação política implica recorrer à Ciência Política, como meio de se propiciar uma abordagem empírica das instituições políticas e não políticas vigentes na sociedade brasileira.

\section{Redes sociais e polaridade política}

Na contemporaneidade, a globalização, em seu sentido multidimensional, propiciou uma crescente possibilidade de interconexão mundial entre populações de diversas e distantes 
regiões geográficas. Tal fato decorreu, principalmente, dos meios modernos de comunicação e do desenvolvimento tecnológico, o que possibilitou maior integração e influência mútua nos níveis sociais e políticos em escala mundial.

Os meios de comunicação de massa implicaram um deslocamento das fronteiras entre grupos e espaços sociais diferentes, privilegiando maior troca de informações e transmissão simultânea de mensagens. E, “com relação à vida política, o impacto midiático sobre as formas de discurso, nas relações entre representantes e representados e nas vias de acesso às carreiras políticas é indiscutível” (MOREIRA, 2016, p. 105).

Com efeito, os meios massivos articularam as práticas de comunicação com os movimentos sociais, passando a incorporar, inclusive, culturas populares. No Brasil, MartinBarbero cita o exemplo da população negra. Por meio do rádio e de discos, os negros tiveram sua cultura transmitida para todos, mostrando a beleza do candomblé e da capoeira (MARTINBARBERO, 2008, p. 242). Outrossim, o autor cita outros meios de comunicação que permitiram que as classes populares ganhassem destaque, como o cinema e o radioteatro. Sustenta que, "para além de seu conteúdo reacionário e do esquematismo de sua forma, o cinema vai ligar-se à fome das massas por se fazerem visíveis socialmente. E vai se inscrever nesse movimento dando imagem e voz à identidade nacional. As pessoas vão ao cinema para se ver [...]" (MARTIN- BARBERO, 2008, 236).

Entretanto, o surgimento da internet, e, em especial, das redes sociais, representou um novo espaço na vida dos cidadãos. Ao entrar nos anos 2000 a internet já tomava e mostrava um importante espaço, que poderia ser usado das mais variadas formas.

Atualmente, esse mundo virtual englobado pela internet é capaz de conectar pessoas a diversos conhecimentos de outras culturas: uma mera rede de amigos (facebook) pode se tornar a maior rede social no mundo. Já o Twitter faz que com 140 caracteres se eleve alguém para herói e rebaixe alguém como vilão com grande facilidade. Do mesmo modo, o Instagram permite compartilhamento de vídeos ao vivo, conhecidos como Lives, e de fotos que, as vezes, passam mensagens mais verossímeis que suas legendas. Assim, a internet passa a ser depositária de toda forma de conhecimento e interações, e ela, em muito, traduz certos fenômenos do mundo real ou ainda mais, substituiu certos comportamentos e troca de informações desse mundo real. 
Neste contexto de realidade tecnológica, a chamada "alfabetização digital" será certamente cada vez mais indispensável para questões de articulação política, de presença social, de proposição cultural, de inovação estética, de ordenação jurídica, de criação identitária no futuro imediato. Montreal (2007, p. 09) já previa que "neste futuro ciberdigital, neste espaço cíbrido, as comunidades virtuais terão importância fundamental na questão política, social, cultural, étnica e mesmo jurídica".

Percebe-se que o avanço tecnológico dos meios midiáticos admite que a sociedade tenha conhecimento amplo dos acontecimentos sociais, econômicos, políticos e jurídicos, e assim possa desenvolver sua consciência ética cidadã. Com efeito, os meios de comunicação permitem que a população saiba de decisões que estão sendo tomadas que podem repercutir na esfera pública, contribuindo para a formação de uma consciência e de uma identidade social.

Neste contexto de realidade tecnológica a chamada "alfabetização digital" será
certamente cada vez mais indispensável para questões de articulação política, de
presença social, de proposição cultural, de inovação estética, de ordenação jurídica, de
criação identitária no futuro imediato (MATUCK, 2008, p. 03).

Cabe, portanto, à dogmática jurídica, calcar agora o ambiente virtual em sua tona de debate, não apenas considerando os reflexos do mundo virtual no real, há que se considerar por óbvio os aspectos reais no virtual, visto a sociedade cada vez estar se virtualizando.

No que diz respeito especificamente ao campo do Direito, nota-se que a mídia vem abordando várias questões jurídicas, levando ao conhecimento da população demandas que envolvam normas, decisões jurisdicionais, atos de gestão da Administração, dentre outros. Sob esse enfoque, Matuck (2008, p. 04), assim dissertou: "propomo-nos deste modo nos tornarmos contendores mais bem informados dos avanços da ciência e da tecnologia e também sujeitos ativos e cientes de nossos direitos atuais e emergentes como cidadãos".

A título de exemplo, a transmissão online, em tempo real, das sessões de julgamento do Supremo Tribunal Federal comporta a possibilidade de que qualquer pessoa acompanhe os debates e as decisões da Corte. Isso gera uma familiaridade entre o Judiciário e os seus jurisdicionados. Da mesma maneira, faz com que os Ministros estejam atentos à repercussão de suas decisões. Ademais, por meio da internet, pode-se ter acesso aos atos do Poder Executivo, como portal da transparência, que consiste em um canal eletrônico de informações que são disponíveis à sociedade acerca das receitas e despesas do estado. Ademais, a sociedade tem acesso às deliberações das comissões legislativas e aos projetos de lei em trâmite no Congresso e nas Assembleias Legislativas, por meio de aplicativos de 
celulares desenvolvidos para tal finalidade ${ }^{3}$, bem como é informada da realização de audiências públicas, podendo se manifestar por meio da internet e comparecer pessoalmente conforme data e horários amplamente divulgados.

Nesse contexto de ampla divulgação da cultura cibernética, dá-se destaque, tendo em vista o objeto deste trabalho, às redes sociais, como forma de a classe popular ganhar visibilidade, garantindo uma participação efetiva, inclusive, nos processos de deliberação política. Sites de redes sociais são gratuitos, livres e permitem grande articulação entre as pessoas de diferentes localidades. Além disso, a difusão do WiFi e do acesso à Internet a custo reduzido por meio de celular tornou a mídia acessível, possibilitando troca de informações que as mídias tradicionais não seriam capazes de proporcionar.

Pode-se dizer que as redes virtuais funcionam como dispositivos de subjetivação que rompem limites do espaço terrestre e permitem maior controle dos discursos por parte dos cidadãos. Marcello (2004, p. 203) aduz que a mídia, aliada ao processo de repetição discursiva, cria condições para a produção de novas discursividades, e, devido ao número ilimitado do crescimento de novas redes, aumentam-se substancialmente processos de subjetivação.

Sobre a construção de processos discursivos, Foucault defende que a mídia assumiu mais um caráter social, permitindo uma ressignificação das relações por meio de instituições (FOUCAULT, 2014, p. 12). Em análise comparativa, as mídias tradicionais (televisão e rádio) davam espaço para práticas de exclusão, uma vez que "não se tem o direito de dizer tudo, que não se pode falar de tudo em qualquer circunstância, que qualquer um, enfim, não pode falar de qualquer coisa" (FOUCAULT, 2014, p. 09). Porém, a propagação de redes online implicou a ascensão de novos atores sociais, que viram no espaço público a possibilidade de reconhecimento, visibilidade e participação dos processos políticos e econômicos em escala mundial.

O que tento demarcar sob esse nome é, primeiramente, um conjunto resolutamente heterogêneo, comportando discursos, instituições, organizações arquitetônicas, decisões regulamentares, leis, medidas administrativas, enunciados científicos, proposições filosóficas, morais, filantrópicas, em suma: tanto o dito como o não dito, aí estão os elementos do dispositivo. O dispositivo, propriamente, é o sistema de relações que se pode estabelecer entre esses elementos (FOUCAULT, 2014, p. 299).

\footnotetext{
${ }^{3}$ Em consulta feita pelos autores em 11 de agosto de 2019 à Loja virtual App Store, disponíveis em Iphones, encontraram-se, dentre outros, os seguintes aplicativos "Mudamos", "colab", "Meu Deputado", "Meu vereador", "ParticipaBR", "Politicus".
} 
Infere-se da citação que a heterogeneização das redes virtuais trouxe maior número de expectadores e atores políticos, sendo justamente esses rearranjos de discursos que formam uma rede de conexões não preestabelecidas que caracteriza o dispositivo. (BRAGA, 2018, p. 84).

Por outro lado, os instrumentos de conexão e interação trouxeram uma série de implicações jurídicas, a partir do momento que as pessoas passaram a recorrer ao mundo virtual como forma de proferirem discursos e opiniões inerentes à esfera política. Em decorrência desses temas que exsurgem com as novas tecnologias, o campo jurídico não pode fechar os olhos à realidade social: o ser humano atual é hiperconectado e esse mundo virtual é o que lhe possibilitou sua inclusão social em deliberações políticas de modo jamais visto (LACERDA, 2017, p. 02)

Desta feita, há casos de repercussão pública, principalmente quando se envolve crimes dolosos contra a vida, em que a mídia aponta opiniões subjetivas em desfavor do acusado, as quais acabam contribuindo para a formação de uma opinião pública, que julga previamente o suspeito como condenado. Recorrentemente, há concreta pressão da mídia com relação a um caso que será julgado perante os Tribunais, como o caso do julgamento de Alexandre Nardoni e Anna Jatobá, condenados pelo homicídio da criança Isabela Nardoni; Suzane von Richthofen com relação a morte de seus pais; caso do julgamento do mensalão junto ao Supremo Tribunal Federal; dentre outros.

Segundo Campos (2012, p. 09), os empresas de comunicação têm como um dos principais objetivos a venda da notícia, e não a garantia de informação livre e imparcial ao destinatário, de modo que, na medida em que uma decisão mais surpreenda e choque o público, maior será a audiência, e, como consequência, maior o interesse em se manter a repercussão do assunto.

Embora não se desconheça efeitos negativos que a internet possa causar em diferentes cenários jurídicos, pretende-se, neste momento, discorrer estritamente ao uso das redes no cenário das eleições presidenciais de 2018. Verifica-se que sites de mídia social como Facebook, Twitter e Instagram - amplamente utilizados durante as campanhas de 2018, seja como forma de os candidatos fazerem sua propaganda política, seja como forma de os eleitores manifestarem sua opinião. As divergências políticas iniciaram-se antes mesmo do ano eleitoral. 
No ano de 2017, um deputado federal em seu sétimo mandato consecutivo manifesta seu interesse em disputar as eleições presidenciais de 2018. Jair Messias Bolsonaro, capitão reformado do exército, se filiou ao Partido Social Liberal (PSL) e passou a ganhar espaço, especialmente por ter uma ampla visibilidade em sua rede twitter.

O que ocorre é que o pré candidato tem várias passagens de escândalos envolvendo homofobia, machismo e ideais fascistas ${ }^{4}$. Ora, em um contexto de prisão de um ex presidente e Impeachment da Presidente Dilma, fatos que implicaram a queda do Partido dos Trabalhadores - PT, e ascensão da popularidade de um ex militar, o resultado não poderia ser outro senão a própria fragmentação da opinião pública.

A partir de então, inicia-se um movimento online que ficou conhecido como "Ele Não”. Ao contrário das manifestações de 2013 e 2015, que se iniciaram virtualmente mas se estenderam às ruas, os protestos contra Bolsonaro ocorreram predominantemente nas redes sociais, por meio da criação de grupos e páginas públicas no Facebook e propagação de inúmeras Hastags no Instagram e Twitter. Por outro lado, outra parte da população, passou a ver no então deputado única alternativa para defender seus interesses econômicos e afastar altos índices de corrupção que se alastraram pelo país. Assim, do mesmo modo, proliferaram-se campanhas online a favor de Bolsonaro.

Pelo fato de o Direito ser uma ciência do espírito (LACERDA, 2017, p. 01), naturalmente tende a certa dificuldade em se relacionar a algo que é essencialmente técnico, Assim como a ciência jurídica se modernizou frente àquelas chamadas novas eras, das revoluções industriais e francesa, do chamado iluminismo e dentre tantas outras, agora ela é chamada a dar mais esse passo visando sempre o bem comum e tendo a cautela de buscar sempre a justiça.

O fator é a se questionar é: até que ponto pode-se atribuir legitimidade aos discursos sociais políticos produzidos nas redes virtuais? Por se tratarem de dispositivos subjetivos, é possível considerá-los no processo deliberativo? Para melhor compreensão do objeto da avença, recorreu-se à doutrina de Habermas, a qual estuda a sociedade a partir da concepção de espaço público para se questionar o monopólio estatal das decisões políticas e sociais.

\footnotetext{
${ }^{4}$ Dentre as polêmicas que o então pré candidato se envolveu, destacam-se ofensas à deputada Maria do Rosário; dedicação, durante o processo de Impeachment, de seu voto a um dos principais coronéis torturadores na época da Ditadura Militar; e desprezo por homossexuais (MARTINS E BOADLE, 2018)
} 


\section{Processo de comunicação e virtualização: a construção de um espaço público}

O pensamento habermasiano propõe que esferas públicas sejam vistas como espaços comunicativos onde informação e ideias circulam; ou seja, um espaço onde pessoas privadas se reúnem para discutir o bem comum e formular a opinião pública. $\mathrm{O}$ autor, conhecido a partir de seu livro Mudança estrutural da esfera pública, publicado originariamente em 1962, criou o conceito de esfera pública e classificou a formação da opinião pública e da legitimação do Estado nas sociedades ocidentais.

Habermas parte da ideia que o poder estatal é um poder público legitimado pelo povo por meio das eleições formais. E, por esse motivo, a opinião pública deve controlar as ações governamentais, permitindo uma gestão democrática das atividades de interesse coletivo. Para se permitir que tais discussões ocorram, pressupõe-se a formação de um espaço público capaz de permitir a acessibilidade das ações legais.

Por meio dessa premissa, o autor conceitua espaço social como uma esfera de pessoas particulares que se reúnem para formar um corpo público, capaz de produz debates por meio argumentos racionais, no intuito de exercer um controle efetivamente subordinado à demanda democrática (HABERMAS, 1974, p. 01). Veja-se que esta definição permite que a esfera pública seja vista como um espaço para que as pessoas se articulem e discutam seus pensamentos sobre as questões sócio-políticas.

Acontece que o autor reconhece a evolução e ascensão da teoria da esfera pública no século XVIII, bem como sua transformação a partir do século XIX, tendo em vista a falta de as pessoas privadas se reunirem no espaço público para regularem questões de seus interesses. (HABERMAS, 2003-b, p. 186-187). É sob essa vertente que o sociólogo passa a criticar a desintegração das esferas e a ascensão da impressa como meio de comunicação detentor do debate público. Sua crítica é que jornais, pelo excesso de sensacionalismo, acaba se aproximando da sociedade ao divulgar informações fáticas como se fossem as únicas verdadeiras, de modo que os cidadãos formem uma opinião prévia.

Com uma rede de comunicação mais comercializada e condensada, com o crescimento dos custos de capital e com o aumento da escala organizacional das instituições editoriais, as vias de comunicação foram canalizadas de forma mais rígida e as oportunidades de acesso à comunicação pública ficaram sujeitas a uma pressão seletiva cada vez mais rigorosa. Com isso, surgiu uma nova categoria de influência, a saber, o poder da mídia, que, usado de modo manipulador, privou o princípio da publicidade de sua inocência (HABERMAS, 2003-b, p. 57-58). 
Todavia, com a imersão da Internet, Habermas propõe uma revisão de sua teoria, a fim de se discutir a possibilidade de reconfiguração da tradicional compreensão da esfera pública no contexto de desenvolvimento mídia eletrônica. (HABERMAS, 2003-b, p. 59). Nesse sentido, passa a perceber que os indivíduos encontram-se ligados por meio de uma "comunidade virtual", fundamentada em diálogos e debates que poderiam, de fato, levar à formação de "opinião pública".

Nesse sentido, a Internet passa a ser vista como um novo meio da esfera pública durante o século XXI, capaz de promover uma "comunidade virtual" na qual as opiniões individuais são consideradas e recebem uma voz, dando ensejo a uma "esfera pública policêntrica", tal como proposto por Habermas (2003-b, p. 63).

É sob essa vertente que o sociólogo alemão argui que a esfera pública midiática é capaz de permitir que os cidadãos tenham opiniões públicas próprias, as quais possam, inclusive, influenciar no processo deliberativo do Poder Público. Para ilustrar, verifica-se que movimentos sociais se constituem em agrupamentos da sociedade civil que permitem que novos atores da sociedade civil, até então negligenciados, possam assumir um papel surpreendentemente ativo e pleno de consequências, quando tomam consciência de uma situação de crise. (HABERMAS, 2003-a, p. 106-107).

Em decorrência disso, a internet possibilita um alargamento ilimitado do espaço público, já que qualquer indivíduo pode emitir suas opiniões) e a livre discussão de temas, tratando-se de espaços de debate público e construção social da realidade, mesmo que virtualmente (ALMEIDA, 2011, p. 13). Ora, a rede de computadores melhorou a comunicação e fomentou a racionalidade crítica, pode ser compreendida como uma esfera pública que fomenta uma sociedade democrática.

Por essas razões, torna-se possível repensar a teoria habermasiana no sentido de revitalizar suas funções democráticas no contexto tecnológico do século XXI. Na verdade, pode-se dizer que as tecnologias podem ser vistas como oportunidade para a esfera pública recuperar funções democráticas por ter novos atores sociais que possam expor seu pensamento racional-crítico e propiciar debates entre um maior número de pessoas. Por causa dos desenvolvimentos no plano de mídia, pode-se dizer que a esfera pública não se limita apenas a uma "interação cara-a-cara" e "encontro um-para-um". Pelo contrário: a virtualização permite acesso às informações de modo muito mais amplo e rápido. 
Trata-se, então, de uma proposta de incremento da politicidade das sociedades modernas, com o intuito de democratizar o discurso e manter uma arena permanente de discussão das questões públicas. Pode-se dizer, então, que Jürgen Habermas vinculou o conceito de democracia aos de participação, procedimento e discurso; bem como estabeleceu que o caráter democrático (e a legitimidade) de uma norma dependiam essencialmente do procedimento adotado, de maneira que estariam presentes se houvesse participação dos destinatários da decisão, sendo-lhes franqueada a possibilidade de se valer do discurso racional. Em suas próprias palavras

Uma interpretação apoiada numa teoria do discurso insiste em afirmar que a formação democrática da vontade não tira sua força legitimadora da convergência preliminar de convicções éticas consuetudinárias, e sim de pressupostos comunicativos e procedimentos, os quais permitem que, durante o processo deliberativo, venham à tona os melhores argumentos (HABERMAS, 2003-a, p. 345).

Desse modo, o uso de avanços tecnológicos de hoje, especialmente a emergência da Internet em suas diferentes plataformas, deve ser utilizado para fomentar diálogo, encontro e solidariedade a todas as pessoas. Trata-se, com efeito, de uma oportunidade para que a esfera pública possa se reconfigurar e reviver as funções democráticas, por meio a ascensão de fóruns deliberativos no ciberespaço, o que coaduna com a ideia de democracia deliberativa proposta por Habermas.

\section{Instituições sociais virtuais como forma de participação popular}

A esfera pública do século XXI congratulou-se com as instituições sociais que, até então, eram desconsideradas em decorrência de seu caráter apolítico e não deliberativo. Isso porque o surgimento da Internet proporcionou às pessoas a chance de se envolverem, novamente, no debate racional-crítico, fomentando discursos políticos, econômicos e sociais.

A transformação do espaço público com o surgimento de diferentes informações tecnologias ganhou destaque no cenário brasileiro no contexto das eleições de 2018, na medida em que diferentes grupos sociais passaram a recorrer às redes sociais como forma de se expressarem politicamente, seja na tentativa de influenciar outras pessoas, seja na tentativa montarem espaços para o debate político. Os brasileiros, especialmente após escândalos envolvendo corrupção e lavagem de dinheiro durante os Governos Lula e Dilma, passou a se preocupar mais com as questões políticas, buscando, além de conhecer, participar das deliberações política-eleitorais. 
No cenário político de 2017, dois opositores se destacavam: Jair Bolsonaro, do PSL e Fernando Haddad, do PT. O primeiro deles utilizava o slogan "Brasil Acima De Tudo, Deus Acima De Todos" e tinha como propostas, dentre outras, liberalismo econômico, imprensa livre e independente, combate à corrupção, redução da maior idade penal para 18 anos, reformulação do Estatuto do Desarmamento e fim da progressão de penas e as saídas temporárias (BRASIL. Tribunal Superior Eleitoral. 2018-a).

Já Haddad utilizou o slogan "O Povo Feliz De Novo" e teve como propostas: políticas inclusivas para grupos vulneráveis, como mulheres, LGBTI+ e deficientes, direito à moradia, redistribuição de renda e reforma tributária, proteção da Amazônia, investimentos em Ciência, Tecnologia e Inovação, dentre outros. (BRASIL. Tribunal Superior Eleitoral. 2018-a). O Plano de Governo era inspirado nos ideais do ex presidente Lula - o qual teve sua candidatura indeferida pelo Presidente da República pelo Tribunal Superior Eleitoral para concorrer às eleições de 2018, tendo em vista a condenação penal que culminou em sua prisão no início daquele ano.

O país, de fato, ficou dividido em dois grupos políticos, o que pode ser amplamente visto com uma simples consulta às principais redes sociais. Para ilustrar o papel das redes, como novas instituições sociais propulsoras da participação social, optou-se por uma metodologia de pesquisa empírica, o que se deu pelo uso de recursos de bancos de dados online, como jornais e redes sociais, como forma de se demonstrar condições formais que propiciaram a criação de uma opinião pública qualificada e organizada.

O primeiro grupo virtual que se formou foi chamado de "Mulheres unidas contra Bolsonaro", por meio do Facebook, em 30 de agosto de 2018, que, segundo o sítio eletrônico da BBC (2018), aderiu mais de mais de 3,88 milhões de participantes ${ }^{5}$. A motivação do grupo era que o candidato insinuava práticas racistas, facistas e ofensivas às mulheres. Céli Regina Jardim Pinto, Doutora em Ciência Política e professora Titular aposentada da Universidade Federal do Rio Grande do Sul aduz que "As redes sociais foram importantes na popularização do feminismo, principalmente o feminismo jovem" [...] "O movimento não é só das mulheres. É um movimento humanitário. A causa é contra o fascismo, o racismo, o esquecimento do que aconteceu na ditadura militar. É a favor da diferença". (BBC. 2018).

\footnotetext{
${ }^{5}$ Cabe mencionar que, em pesquisa ao facebook feita pelos autores em 12 de agosto de 2019, aparentemente, não se encontrou a página originária. Na verdade, verificaram-se os grupos @ mulheresunidascontrabolsonaro, com 154.553 seguidores e @ mulherescontraofascimo, com 268.321 seguidores
} 
Já nas redes sociais Instagram e Twitter, passou-se a difundir diversas Hastags contra o candidato: \#EleNão, \#EleNunca, \#MulheresContraOBolsonaro. Segundo informado na Revista Veja São Paulo, hashtag \#MulheresContraOBolsonaro entrou nos trending topics do Twitter no Brasil no dia 16 de setembro de 2018, faltando poucos dias para as eleições. (VEJA. 2018). A adesão fora tão grande que artistas nacionais e internacionais também passaram a postar fotos, vídeos e frases em seus canais sociais convidando outros eleitores a se unirem a eles.

Em pesquisa ao Instagram, encontraram-se postagens dos seguintes famosos: Fernanda Paes Lema (@fepaesleme), Rachel Sheherazade (@rachelSherazade), Daniela Mercury (@danielamercury), Fernanda Lima (@fernandalimaoficial), Patricia Pillar (@ patriciapillar). Na esfera internacional, visualizaram-se postagens dos artistas Ellen Page (@ellenPage), Édgar Ramírez (@edgarramirez25). Por meio da ferramenta Stories $^{6}$ (que permite que a postagem permaneça por 24 horas no Instagram), Madonna (@madonna) utilizou a frase "Ele não vai nos desvalorizar. Ele não vai nos oprimir (TERTO, 2018). Ele não vai nos calar", seguida da hashtag: \#endfascism (fim do fascismo). Sasha Meneghel (@sashameneghel) e Bruna Marquezine (@brumarquezine) também recorreram aos Stories e manifestaram-se contra o candidato. (WARKEN, 2018).

Em pesquisa ao twitter, encontrou-se a celebridade Cher (@cher) que assim se manifestou: "Triste que o Brasil está enfrentando o seu próprio Trump. Um candidato homofóbico e racista está liderando as campanhas. Significaria muito se todos nós pudéssemos compartilhar esse \#EleNão para apoiar isso". O produtor musical americano Diplo (@diplo) compartilhou imagem escrito "ele não" seguida da hastag em seu perfil. Ainda, arrolam-se perfis de famosos como Deborah Secco (@dedesecco), Pitty (@pitty), Alfonso Herrera (@ponchouhd), que, por meio de frases e fotos aderiram ao movimento "Ele Não".

Em contrapartida, ascenderam-se movimentos também a favor de Bolsonaro e contra Haddad. Nas redes sociais, criaram-se as hashtags \#elesim e \#somosbolsonaro17, que, segundo a Revista Época, até 02 de outubro, contavam com 137 mil e 441 mil citações, respectivamente (STACHEWSKI, 2018). Do mesmo modo, ascenderam-se grupos sociais no Facebook em prol do candidato, como Mulheres Com Bolsonaro ${ }^{7}$ e Todos com Bolsonaro ${ }^{8}$.

\footnotetext{
${ }^{6}$ Tendo em vista que as postagens dos Stories expiram em 24h, não foi possível a realização de uma pesquisa empírica de forma direta a esta rede social. Para apuração desses dados, utilizaram-se fontes secundárias.

${ }^{7}$ Em pesquisa feita pelos autores em 18 de agosto de 2019, encontrou-se o Grupo fechado, com 1,5 milhões de participantes, e a descrição "Grupo feito pra mulheres de fibra e coragem que não precisam do feminismo e
} 
Segundo pesquisa da FGV DAPP, em que foram alisados mais de 130 milhões de tuítes e de 163 milhões de interações nas páginas dos 13 candidatos ao cargo de presidência, entre 25 de julho e 30 de outubro. (FGV, 2018). Constatou-se que, até início de setembro, o nome do Bolsonaro fora encontrado entre 200 mil e 400 mil menções diárias no Twitter. Após o ataque sofrido pelo candidato em Juiz de Fora ${ }^{9}$, em 06 de setembro, seu nome fora citado 4 milhoes de vezes, centralizando sua presença como ator central, sem concorrência expressiva (FGV, 2018).

Em análise feira de 25 de outubro de 31 de outubro, via Twitter, foram constatados diferentes perfis e postagens, especialmente após o resultado das eleições, no segundo turno, em 28 de outubro de 2018, com a vitória de Bolsonaro:

\begin{tabular}{|l|l|}
\hline \multicolumn{2}{|l|}{ Mapa de interações sem robôs sobre presidenciáveis. (4.117.531 retuítes) } \\
\hline Núcleo Pró-Haddad & $37,1 \%$ \\
\hline Grupo de apoio a Bolsonaro & $18,5 \%$ \\
\hline $\begin{array}{l}\text { Oposição a Bolsonaro articulada a partir de } \\
\text { perfis de impressa }\end{array}$ & $15,2 \%$ \\
\hline Memes e publicações contrárias a Bolsonaro & $11,0 \%$ \\
\hline Crítica aos opositores do presidente eleito & $9,2 \%$ \\
\hline $\begin{array}{l}\text { Apoio de políticos e figuras públicas } \\
\text { estrangeiras a Bolsonaro }\end{array}$ & $3,5 \%$ \\
\hline
\end{tabular}

(Fonte: FGV DAPP, 2018 - adaptado)

Com relação à repercussão de notícias, de 25 a 31 de outubro, foram registradas quase 101,4 milhões de interações (curtidas, comentários e compartilhamentos), de forma preponderante acerca de Bolsonaro (FGV, 2018).

Engajamento das notícias sobre Bolsonaro e Haddad no Facebook e no Twitter - 25.out a 31.out

\begin{tabular}{|l|l|l|l|}
\hline Candidato & Facebook & Twitter & Total \\
\hline Bolsonaro & 68.465 .294 & 980.160 & 69.445 .454 \\
\hline
\end{tabular}

defendem o Capitão Bolsonaro pra presidente do Brasil!!! Por um Brasil melhor, é BOLSONARO PRESIDENTE!!! \#MudaBrasil \#MudaDeVerdade \#MulhersComBolsonaro \#BolsonaroPresidente"

${ }^{8}$ Em pesquisa ao Facebook, feita em 18 de agosto de 2019, foram encontrados vários grupos com o título "Todos com Bolsonaro". O mais expressivo deles contava com 24 mil membros.

${ }^{9}$ No dia 06 de setembro de 2018, Jair Bolsonaro levou uma facada durante um ato de campanha na cidade de Juiz de Fora, MG, sendo submetido a cirurgias tendo em vista lesões em seu intestino. O agressor suspeito foi preso na mesma data e o candidato foi liberado após 10 dias de internação. (GLOBO, 2018) 


\begin{tabular}{|l|l|l|l|}
\hline Haddad & 31.462 .610 & 487.544 & 31.950 .154 \\
\hline
\end{tabular}

(Fonte: FGV DAPP, 2018 - adaptado)

Paralelamente a este cenário, surgiram inúmeras notícias virtuais falsas ou fortemente tendenciosas, chamadas de Fake News, na tentativa de enobrecer ou desmerecer determinado candidato. Às vésperas do primeiro turno, desinformações deliberadas tramitaram por meio das mídias virtuais e, devido à alta carga de informações ou ao forte clamor emocional dos cidadãos, eram pouco questionadas com relação à veracidade, sendo adotadas como verdades absolutas e compartilhadas nas redes de maneira instantânea. Para ilustrar, foram compartilhadas notícias como: que Fernando Haddad teria sido o ministro responsável pela distribuição de um livro no qual um dos textos tratava de incesto; que a candidata Marina Silva teria se envolvido em casos de corrupção; que Bolsonaro disse que não precisava do voto de eleitores do Nordeste (VALENTE, 2018).

Se não bastasse, entre o primeiro e o segundo turno, houve disseminação de notícias questionando, inclusive, quebra de sigilo e possível fraude das urnas eletrônicas. Em decorrência desta situação, o Tribunal Superior Eleitoral divulgou em seu sítio eletrônico uma seria de esclarecimentos acerca das Fake News relacionadas às eleições, as quais foram apuradas por meio de Denúncia e apuradas por meio de agências de checagem de conteúdo. Dentre elas, pode-se mencionar: "Mesário pode falsificar assinatura de eleitores e, assim, anular o voto", "Urnas programadas de acordo com horário de verão", "Eleitor não consegue votar para presidente", "Boletim de urna com 9.909 votos, "Urna autocompleta o voto", "Se verificadas as fraudes, Exército convocará novas eleições em cédulas de papel”. (BRASIL. Tribunal Superior Eleitoral. 2018-c).

Embora Bolsonaro tenha vencido as eleições, com 55,13\% (57.797.847 votos válidos) de votos apurados no segundo turno, contra 44,87\% (47.040.906) (BRASIL. Tribunal Superior Eleitoral. 2018-b) em favor de Haddad, várias críticas, inseridas nas redes virtuais, persistiram em desfavor do novo presidente ${ }^{10}$. Apesar de o cenário brasileiro ter se encontrado em um impasse virtual, pode-se dizer que as redes sociais foram capazes de propiciar ampla participação dos cidadãos durante o processo eleitoral, de maneira que dificilmente aconteceria se tal atuação ficasse restrita à mídia tradicional.

10 Em consulta ao Instagram, foram encontrados os seguintes dados, em números aproximados: \#seremosresistência: 20.000 publicações; \#elenaomerepresentanta: 20.900 publicações; \#mulherescontraofacismo: 18.200 publicações 
Nesse cenário, é de se notar, pois, que a concepção de uma esfera pública informalmente organizada, tal como ocorreu com o espaço produzido pelas redes sociais, pode ser vista como um fator inspirativo para a consolidação de uma democracia deliberativa, uma vez que concebem legitimidade de decisões políticas como estando dependente das discussões públicas que as precederam. (SILVA, 2002, p. 45). Ora, se Habermas argumenta ser possível medir ou avaliar a legitimidade da influência que a opinião pública detém sobre o sistema político, de acordo com a maior ou menor racionalidade comunicativa, é possível inferir que as redes sociais nada mais são do que efetivos meios de participação popular, legitimada não pelo voto, e sim pela própria sociedade que deposita nas redes sociais sua confiança como forma de propiciar um discurso político construtivo.

\section{Conclusão.}

No contexto do século XXI, as redes sociais tornaram-se uma plataforma responsável por envolver discursos políticos de acordo com as características estruturais de uma esfera pública habermasiana. Essa perspectiva permite que os cidadãos reconheçam sua participação no discurso político on-line e se envolvam conscientemente com mídia como meio de se propiciar mudanças políticas.

O período eleitoral brasileiro de 2018 foi marcado por alta participação das mídias sociais alternativas, com destaque ao Facebook, Instagram e Twitter, superando oligopólios controlados pelas mídias tradicionais (televisão e rádio). Além do fato de a estrutura geral da mídia social parecer fornecer acesso ilimitado a informações em nível mundial, sabe-se que a internet é relativamente acessível, pois permite tanto a participação quanto a aquisição de informações livres de influências externas.

Com efeito, percebe-se que as mídias sociais podem revitalizar a esfera pública permitindo que as pessoas compartilhem discursos, informações e opiniões pessoais sobre o cenário político. Esse novo fenômeno fez a comunicação tornar-se um processo muito mais democrático, funcionando como um palco para a política do discurso, capacitando a inclusão de pessoas que eram vistas como excluídas dos processos deliberativos no passado.

Nesse sentido, embora as sociedades contemporâneas ocidentais estejam (e, provavelmente, sempre estarão) organizadas em torno de uma democracia representativa político-partidária, tal fato não implica que dela precisem ser reféns, convivendo com crises de 
legitimidades mais graves do que as que já lhe são inerentes. Na verdade, nota-se que as mídias sociais encorajam o engajamento cívico em maneiras diferenciadas, remetendo à ideia de esfera pública estrutural, definida por Jurgen Habermas (1974) como uma arena onde os cidadãos discutem assuntos públicos.

Este trabalho apresenta-se como uma contribuição no sentido de levantar a reflexão de que o Estado Democrático de Direito deve ser amistoso a uma democracia complexa, pelo qual o viés indireto (representação) pode ser exercido de maneira harmônica com o viés direto (tal como ocorre por meio de discursos impulsionados pelas redes sociais).

\section{Referências bibliográficas.}

ALMEIDA, Gabriela Maria Farias Falcão de. As mudanças do espaço público e suas relações com os media. XVI Congresso de Ciências da Comunicação na Região Sudeste realizado de 12 a 14 de maio de 2011. Intercom. Sociedade Brasileira de Estudos Interdisciplinares da Comunicação. Disponível http://www.intercom.org.br/papers/regionais/sudeste2011/resumos/R24-0934-1.pdf Acesso em: 11 abr. 2020.

BBC. \#EleNão: A manifestação histórica liderada por mulheres no Brasil vista por quatro ângulos. 30 setembro 2018. Disponível em:. https://www.bbc.com/portuguese/brasil-45700013 Acesso em: 11 abr. 2020.

BRASIL. Tribunal Superior Eleitoral. Eleições 2018: Propostas de governo dos candidatos ao cargo de Presidente da República. (2018-a). Disponível em: http://www.tse.jus.br/eleicoes/eleicoes-2018/propostas-de-candidatos Acesso em: 11 abr. 2020.

BRASIL. Tribunal Superior Eleitoral. Eleições 2018. Divulgação de Resultados de Eleições (2018-b). Disponível em: http://divulga.tse.jus.br/oficial/index.html Acesso em: 11 abr. 2020. 
BRASIL. Tribunal Superior Eleitoral. Eleições 2018. Esclarecimentos sobre informações falsas. (2018-c). Disponível em: http://www.tse.jus.br/hotsites/esclarecimentos-informacoesfalsas-eleicoes-2018/ Acesso em: 11 abr. 2020.

BRAGA, José Luiz. Interagindo com Foucault: Os arranjos disposicionais e a comunicação. Questões Transversais. Revista de Epistemologias da Comunicação. Vol. 6, nº 12, julhodezembro/2018

CAMPOS, Marco Antonio Magalhães De. A influência da mídia no Processo Penal. Monografia. Escola da Magistratura do Estado do Rio de Janeiro. Rio de Janeiro, 2012. Disponível em:

http://www.emerj.tjrj.jus.br/paginas/trabalhos_conclusao/1semestre2012/trabalhos_12012/marc oantoniocampos.pdf. Acesso em: 11 abr. 2020.

STACHEWSKI, Ana Laura. ÉPOCA. Movimentos contra e a favor de Bolsonaro somam 2,45 mi de menções no Twitter em três dias. Revista Época. 02/10/2018. https://epocanegocios.globo.com/Brasil/noticia/2018/10/movimentos-contra-e-favor-debolsonaro-somam-245-mi-de-mencoes-no-twitter-em-tres-dias.html Acesso em: 11 abr. 2020.

FOUCAULT, Michel. A ordem do discurso. Tradução: Laura Fraga de Almeida Sampaio. São Paulo: Edições Loyola, 2014.

GLOBO, Jair Bolsonaro leva facada durante ato de campanha em Juiz de Fora. 06/09/2018. Disponível em https://g1.globo.com/mg/zona-da-mata/noticia/2018/09/06/ato-decampanha-de-bolsonaro-em-juiz-de-fora-e-interrompido-apos-tumulto.ghtml Acesso em: 11 abr. 2020 .

HABERMAS, Jürgen. The Public Sphere: An Encyclopedia Article. New German Critique, No. 3, 1974. 
HABERMAS, Jürgen. Direito e Democracia: entre faticidade e validade. Volume II.. Rio de Janeiro: Tempo Brasileiro, 2003-a

Mudança estrutural na esfera pública: investigações quanto a uma categoria da sociedade burguesa. 2.ed. Rio de Janeiro: Tempo Brasileiro, 2003-b

LACERDA, Bruno Zampier Torquata. Bens Digitais: Cybercultura, Redes Sociais, E-mails, Músicas, Livros Milhas Aéreas, Moedas Virtuais. 1a Ed. Editora Foco. 2017.

MARCELLO, Fabiana de Amorim. O conceito de dispositivo em Foucault: mídia e produção agonística de sujeitos-maternos. Educação e Realidade. 29(1):199-213 jan/jun 2004

MARTÍN-BARBERO. Jesús. Dos meios às mediações: Comunicação, cultura e hegemonia. Rio de Janeiro: Editora UFRJ, 2008

MARTINS, Lais, BOADLE, Anthony. Veja algumas das declarações mais polêmicas de Bolsonaro. GLOBO. Publicado em 17/05/18. Disponível em: https://extra.globo.com/noticias/brasil/saiba-mais-veja-algumas-das-declaracoes-maispolemicas-de-bolsonaro-22692579.html Acesso em: 11 abr. 2020.

MATUCK, Arthur, Uma prospectiva política para um multiverso digivirtual: direitos humanos às tecno-linguagens. In.: SANTAELLA, Lucia; ARANTES, Priscila. Estéticas Tecnológicas: novos modos de sentir. São Paulo: Educ, 2008.

MONTREAL, Artur Matuck. Uma prospectiva política para um multiverso digivirtual: direitos humanos às tecno-linguagens. Universidade de São Paulo. Direitos Tecnolinguagens. 2007. Disponível em: https://edisciplinas.usp.br/pluginfile.php/108631/mod_resource/content/2/Direitos\%20tecnolin guagens.pdf Acesso em: 11 abr. 2020. 
MOREIRA, Talita Lucarelli. A política em tela: o discurso dos presidenciáveis sobre as manifestações de junho de 2013 nos programas televisivos do horário gratuito de propaganda eleitoral. Comunicação \& Mercado/UNIGRAN - Dourados - MS, vol. 05, Caderno Especial, p. 104-114,jan-jun 2016.

SILVA. Filipe Carreira da (Org). Espaço Público em Habermas. Coleção Estudos e Investigações vol. 26. Imprensa de Ciências Sociais. Lisboa, Portugal, 2002

TERTO, Amauri, Além de Roger Waters: 15 artistas internacionais que se manifestaram contra Bolsonaro. Huffpost. 12/10/2018. Disponível em: https://www.huffpostbrasil.com/2018/10/12/alem-de-roger-waters-15-artistas-internacionaisque-se-manifestaram-contra-bolsonaro_a_23558199/ Acesso em: 11 abr. 2020.

VALENTE, Jonas. ONDA de frio recorde assola os Estados Unidos. Agência Brasil, 06 de out. 2018. Disponível em: http://agenciabrasil.ebc.com.br/geral/noticia/2018-10/um-dia-daeleicao-fake-news-sobre-candidatos-inundam-redes-sociais. Acesso em: 11 abr. 2020.

WARKEN, Julia. 40 famosas que se posicionaram contra Jair Bolsonaro. Abril. 18 set 2018, Disponível em: https://mdemulher.abril.com.br/famosos-e-tv/famosas-que-se-posicionaramcontra-jair-bolsonaro/ Acesso em: 11 abr. 2020. 